Note:

\title{
Economic Systems and the Environment
}

\section{Shamyla Chaudhry}

In any economic system, be it a free market or a command economy, the elementary functions of production, distribution and consumption take place within the natural world. The natural world provides the raw materials and the energy inputs for the production process whereas production and consumption leave "residuals" or waste products which go back into nature. The manner in which the residuals are handled will infact tell us how they may lead to pollution or the degradation of the natural environment.

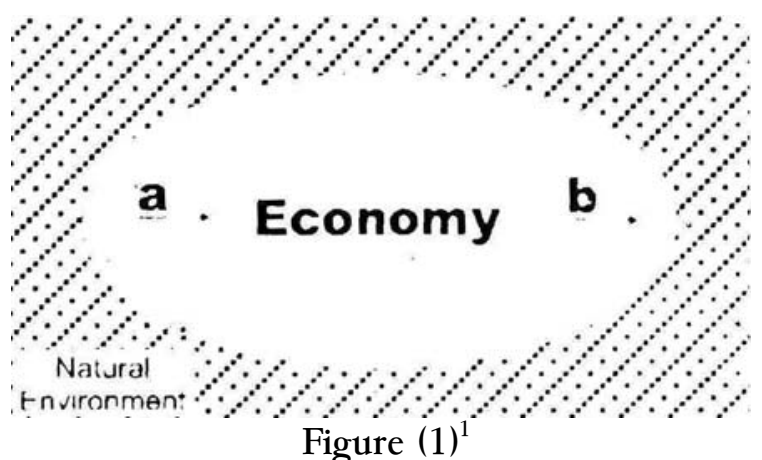

Figure (1) explains the basic link between nature and the economy, (a) explains nature in its role as a product of raw materials and (b) explains what the impact of residuals is on the natural world. Therefore we can see that environmental economics draws from two angles. Primarily it is the study of waste flow management and secondly, it studies the impacts of human activity on environmental resources. Thus one's misconception of environmental problems only being constrained to pollution are removed. Infact, environmental economics focuses not only on pollution oriented problems but also looks at issues such as habitat disruption caused by human activities in an economic system.

A good example of this is a housing development scheme which will disrupt the natural habitat and at the same time bring an array of problems such as sanitation, house waste disposal, etc. Analysing the environment from the perspective of an economic system we have to establish how this

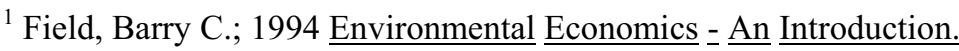


system's working will affect the environment's natural resources, both renewable as well as non- renewable resources. Human activities, within an economic system have substantially increased the rate of species / natural resources extinction. Most of our natural renewable resources are heavily 'time dependent'. This means that they are spread over time, so why do we cut a tree today? We will have to wait atleast $15-20$ years to replace the tree. But in the case of natural non- renewable resources we can work within the framework of tradeoffs between the present and the future. This means we know that once we use all the petrol reservoirs there is no process for their replenishment. So it is our option to utilise a nonrenewable resource to its maximum given a time span and not necessarily exhaust all the resources at one present period of time but save for the future and coming generations.

Figure (2) is a more complex version of Figure (1). The elements within the circle are the same basic parts which represent the economic system, the whole of which is encapsulated within the natural environment. The 'producers' category includes all entities that convert inputs into outputs, in short all entities in the system including the consumers themselves. The primary inputs - the raw materials drawn upon from the natural environment by the producers are fluids such as water and petroleum, minerals and gases of various types such as natural gas and oxygen. Production and consumption activities will create 'residuals'. These may be emitted into the air or water or simple disposed off on land. The producers list is incredibly long; $\mathrm{SO}_{2}$, volatile organic compounds, toxic solvents to particulate matter of all types, etc. Consumers are also responsible for huge quantities of residuals, mainly domestic sewage and automobile emissions. The equation simply shows the fundamental balance.

$$
\begin{gathered}
\mathrm{M}=\mathrm{R}_{\mathrm{p}}^{\mathrm{d}}+\mathrm{R}_{\mathrm{c}}^{\mathrm{d} 2} \\
\text { Inputs = Outputs }
\end{gathered}
$$

\footnotetext{
${ }^{2}$ All flows must be made in terms of mass in order to make a direct comparison.
} 


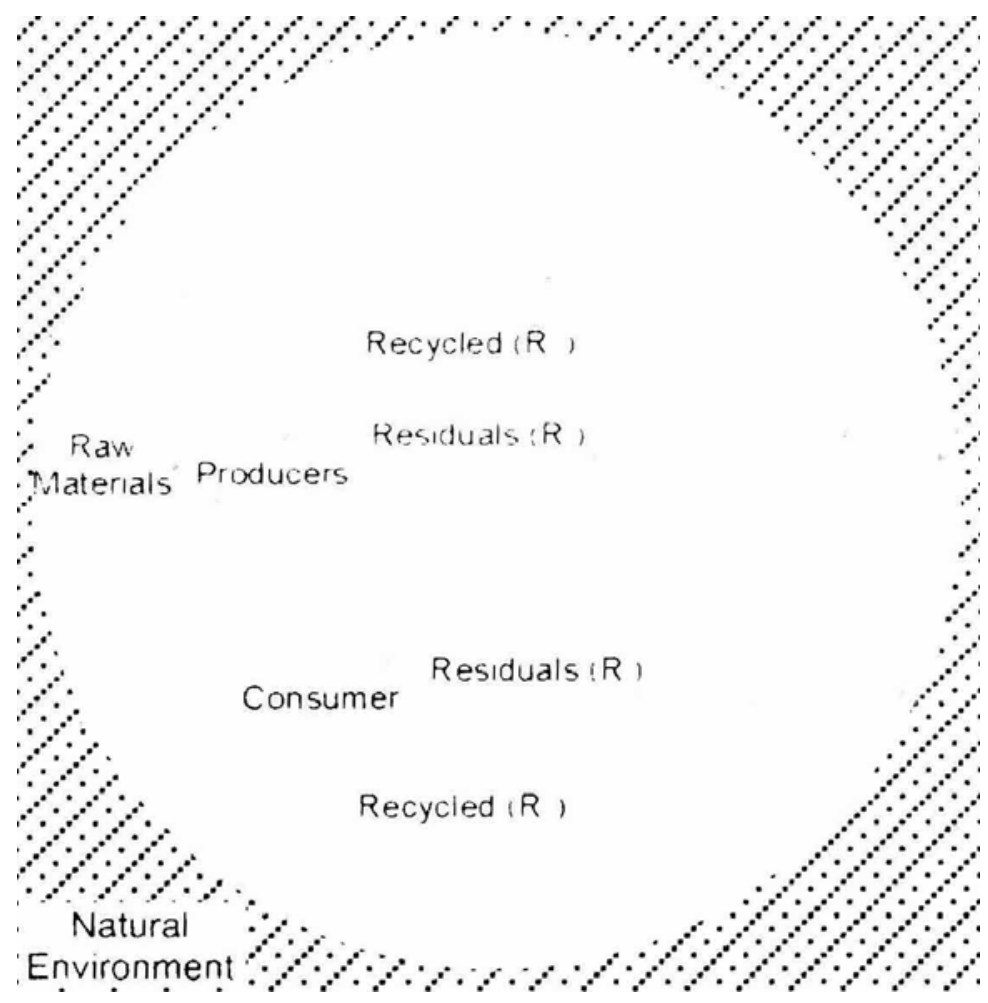

Figure $(2)^{3}$

The relationship essentially draws from the two basic sides of environmental economics. This implies that first you draw on the natural environment for your inputs and secondly, when both activities that is consumption and production ${ }^{4}$ take place the residuals are discharged back into the natural environment. If we want to reduce the mass residuals that are discharged into the environment we first have to reduce the quantity raw materials taken into the system.

If

$$
\mathrm{M}=\mathrm{R}_{\mathrm{p}}^{\mathrm{d}}+\mathrm{R}_{\mathrm{c}}^{\mathrm{d}}
$$

\footnotetext{
${ }^{3}$ Field, Barry C.: 1994 Environmental Economics - An Introduction.

${ }^{4}$ In these cases we can consider producers and consumers as being the same people they both represent the economic system.

${ }^{5}$ (Note that $\mathrm{Ct}=\mathrm{Re}$ i.e. everything that flows to the consumption sector will end up residual from that sector )
} 
If seen more closely

$$
\mathrm{M}=\mathrm{G}+\mathrm{Rp}-\mathrm{R}_{\mathrm{p}}^{\mathrm{r}}-\mathrm{R}_{\mathrm{c}}^{\mathrm{r}}
$$

This simply says that the quantity of raw materials is equal to the output together with production residuals minus the recycled residuals from the consumption and production sectors.

Thus, there are three main ways of reducing the amount of raw materials (that we draw from the natural environment) thus reducing the residuals discharged (into the natural environment).

First we can start by reducing ' $G$ '. If one can reduce or atleast contain the rate of growth of goods and services produced in an economy, we can directly reduce the amounts of raw materials needed for the production process. This approach focuses on the natural resource economics side but why do we analyse it from an environmental economics perspective and assume that all other flows remain the same? We can reduce the amount of residuals discharged into the natural environment. By reducing or atleast containing the growth of goods and services, economists have sought to reach this goal by advocating "zero population growth ${ }^{6}$. A slow growing population or a stationary population can make it easier to control environmental impacts but it does not ensure this because of two main reasons. First, a stagnant population can grow economically, thus increasing the demand for raw materials. Second, environmental impacts can be long run and cumulative in nature so a stagnant population will gradually degrade the environment. But empirical studies justify that population growth will often worsen the environmental impacts of a particular economy. The US economy has a slowly growing population but still the number of cars have increased and thus the emissions from them have also increased. Logically, what has happened is that even though emissions of pollutants per car have decreased because of the use of emission control technologies, the sheer growth of cars on the highways has led to an increase in the total quantity of automobile emissions.

By reducing ' $G$ ' we can ensure a better environmental quality for future generations. Simply, the less the ' $G$ ' the less will be the residuals and thus the less the accumulation of these residuals. Using the production possibility curve for current and future generations we can show the basic relationship.

\footnotetext{
${ }^{6}$ For example, see Human E. Daly, Steady State Economics. Second Edition with New Essays, Island Baess, Washington DC, 1991.

${ }^{7}$ Lahore School of Economics, 1997; "Environmental Problems in Kalchi Abadis - Case Study."
} 
In (a), we can increase consumption from $\mathrm{C}_{1}$ to $\mathrm{C}_{2}$ bu at a cost of lower environmental quality i.e. from $e_{1}$ to $e_{2}$. In (b), the future finds itself on the inner production possibility curve (PPC), where we can have the same consumption $\mathrm{C}_{2}$ but only at a lower level of environmental quality e, than we have today i.e. e-i. Therefore, why do we want our future generations to enjoy the same environmental quality that we have enjoyed i.e. $\mathrm{e}_{2}$ ? They will have to cut consumption to a lower level $\mathrm{e}_{3}$.

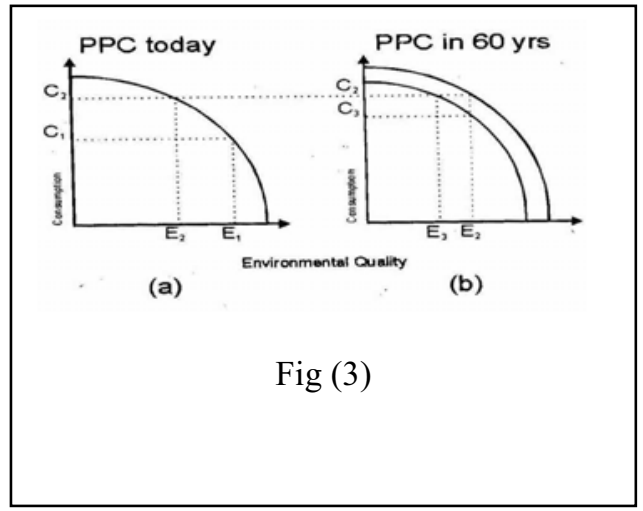

In order that our future generations have a better environmental quality, we have to reduce 'G' today.

The second way of reducing the intake of inputs and therefore residual discharge is to reduce the production residuals. This can be done in two main ways. First, invest and adopt new technologies that produce smaller amounts of residuals per unit of output produced. Secondly, we can shift the internal composition of output i.e. C includes both goods and services. Therefore, move from goods/commodities to service oriented industry. The size of the so-called "information sector' is an example. Most developed nations have had this transition over the last half of the century. It is not that these new sectors produce no significant residuals but on the whole, these sectors have a relatively smaller waste disposal problem than the traditional industries that they have replaced. The last way to reduce the intake of raw materials and hence reduce the residuals is to replace recycled material for virgin materials $(M)$. Simply increase $\left(R_{p}^{r}+R_{p}^{c}\right)$. A very commonly used recycled residual is that of paper. There is no need to cut down trees for additional paper but the use of recycled paper is more advantageous. But we have to remember that recycling can never be perfect as the recycling process itself can create residuals. The ultimate goal is to reduce the damages caused by the discharge of production and consumption residuals. Reducing the total quantity of these residuals is one way of doing this. The relationships discussed indicate the basic ways in which we can achieve this goal striving to adapt to the fundamental balance of the natural world and the economic system. 
134 The Lahore Journal of Economics, Vol.3, No.1

\section{References}

Field, Barry C., 1994 Environmental Economics - An Introduction. McGrav Hill International Edition, New York.

Lahore School of Economics, 1997 "Environmental Problems in Katch Abadis - Case Study".

Ayres, Robert U.; Resources, environment and the Energy Balance Principle, John Wiley and Sons, New York, 1978.

Herman E. Daly, Steady State Economics, Second Edition with New Essays Island Press, Washington D.C. 1991. 